\title{
Assessment of the relationship between frailty syndrome and the nutritional status of older patients
}

This article was published in the following Dove Press journal:

Clinical Interventions in Aging

\author{
Marta Muszalik' \\ Mateusz Gurtowski' \\ Halina Doroszkiewicz ${ }^{2}$ \\ Robbert JJ Gobbens ${ }^{3-5}$ \\ Kornelia Kędziora- \\ Kornatowska' \\ 'Department of Geriatrics, Collegium \\ Medicum in Bydgoszcz, Nicolaus \\ Copernicus University in Torun, Toruń, \\ Poland; ${ }^{2}$ Department of Geriatrics, \\ Medical University of Bialystok, Białystok, \\ Poland; ${ }^{3}$ Faculty of Health, Sports and \\ Social Work, Inholland University of \\ Applied Sciences, Amsterdam, the \\ Netherlands; ${ }^{4}$ Zonnehuisgroep \\ Amstelland, Amstelveen, the \\ Netherlands; ${ }^{5}$ Department of Primary \\ and Interdisciplinary Care, Faculty of \\ Medicine and Health Sciences, University \\ of Antwerp, Antwerp, Belgium
}

Correspondence: Marta Muszalik Department of Geriatrics, Collegium Medicum in Bydgoszcz, Nicolaus Copernicus University in Torun, ul. Marii Curie-Sklodowskiej 9, Bydgoszcz 85-094, Poland

Tel +48525854900

$\mathrm{Fax}+48525854921$

Email muszalik@cm.umk.pl
Objective: The aim of this study was to assess the relationship between frailty syndrome and the nutritional status of older patients.

Material and methods: This cross-sectional study was conducted in a sample of 120 patients hospitalized at the Geriatric Clinic between January 2017 and May 2017. The research tools were the Frailty Instrument of the Survey of Health, Ageing and Retirement in Europe (SHARE-FI), including relevant anthropometric measurements and muscle strength measurement, and the Mini Nutritional Assessment (MNA). All the calculations were performed using the Statistica 10.0 program. The $p$-values lower than 0.05 were considered as statistically significant.

Results: The mean age of the participants was 71 years $(\mathrm{SD}=9.03)$. Most participants were from urban areas. More than half of the participants $(53.3 \%)$ were women. Based on the SHARE-FI, the frailty syndrome was found in $33.3 \%$ of the participants. The mean value in the MNA scale was 24.4 points $(\mathrm{SD}=3.4)$. The frailty syndrome was significantly correlated to gender $(p<0.025)$, financial status $(p=0.036)$ and MNA $(p<0.01)$ score. A statistically significant difference was observed between gender $(p=0.026)$, financial status $(p=0.016)$, place of living $(p=0.046)$ and MNA score.

Conclusion: This study confirmed significant correlations between the frailty syndrome and the nutritional status of older adults. In terms of prevention and clinical application, it seems important to control the nutritional status of older people and the frailty syndrome. The above-mentioned scales should be used to evaluate patients, analyze the risk and plan the intervention for that group of patients.

Keywords: frailty syndrome, nutritional status, older adults, MNA, SHARE-FI

\section{Introduction}

The population of older adults is constantly growing, both in Europe and all over the world. The most common medical problems faced by older people are reduced functional capability and morbidities. Since the early twenty-first century, international geriatric studies describe the frailty syndrome. ${ }^{1,2}$

Statistically, 9.5\% of older adults residing in the United States of North America have been diagnosed with frailty syndrome. Research results have shown that frailty occurs in $7 \%$ of older adults aged $65+$ and in $30 \%$ aged $80+$. The incidence of frailty in European society is between $5.8 \%$ and $27.3 \%$, whereas the pre-frail condition occurs in $34.6 \%$ to $50.9 \%$ of the older adults population. ${ }^{3}$ In the Longitudinal Aging Study Amsterdam, the Dutch researchers found frailty 
syndrome in $19 \%$ of participants aged 65 years and older. In a Spanish study, frailty syndrome was diagnosed in $20 \%$ of people over 70 years of age. ${ }^{4}$

Fried et al, pioneers in studying frailty syndrome, define it as "a biologic syndrome of decreased reserve and resistance to stressors, resulting from cumulative declines across multiple physiologic systems, and causing vulnerability to adverse outcomes." et al symptoms that help recognize frailty syndrome are undesired loss in body mass, reduced muscle strength, exhaustion, slowness and low physical activity. ${ }^{5}$ Frailty syndrome can be confirmed if at least three of the abovementioned five criteria occur. The occurrence of one or two factors indicates the pre-frail status. Geriatricians and other medical care professionals apply the criteria of evaluation of the risk of frailty syndrome; however, currently, there is no consensus regarding the definition of this syndrome. $^{5}$

There are several instruments to screen the risk of frailty syndrome. The assessments include physical criteria, neurological assessment, psychological symptoms and laboratory test outcomes. ${ }^{6}$ Well-known instruments to identify frailty are based on the phenotypic model by Fried et al or the deficit accumulation model. The second model, also known as the frailty index (FI), is calculated as the coefficient/product/relationship of the number of deficits the person represents divided by the sum of deficits taken into consideration in the calculations. ${ }^{5,7,8}$ An example of such an instrument is the Frailty Instrument of the Survey of Health, Ageing and Retirement in Europe (SHARE-FI). ${ }^{3}$

Studies on the frailty syndrome show that some older adults have a good level of functional reserves and psychosocial support. No frailty phenotype is found in this group. The other group is patients with a low level of physiological reserves and poor psychosocial support. In this group, the risk of frailty is very high. Frailty can also occur in the former group because of a serious depression episode. According to gerontologists, frailty syndrome is marked by reduced immunity to stressors, resulting in the exhaustion of functional reserves of the organism that leads to frailty. Frailty syndrome has three stages: the early stage of diagnosis, the intermediate stage characterized by some limitations and the late stage with serious limitations in function. ${ }^{1,5,9,10}$

The causes of frailty syndrome are not fully known. As the person advances in age, their physiological reserves decline. There are many risk factors of the frailty syndrome. Well-known risk factors such as high age and sex (women), several social and behavioral factors (lower education, lower marital status, living arrangements, bad life style, smoking status and alcohol use) are significantly associated with frailty. ${ }^{11,12}$

Some disorders in the musculoskeletal system and reduction in muscle mass and strength lead to sarcopenia. Obesity is one of the risk factors because physical ability is then reduced through the deposition of adipose tissue in muscles. As frailty syndrome advances, functional capability and independence decrease; multiple morbidities intensify; and the risk of falls, institutionalization and premature death increases. ${ }^{13}$

The need for dietary changes and physical activity is often highlighted in the prevention of frailty syndrome. Resistance exercises are especially important, as they can prevent the development of sarcopenia and improve physical capability. Studies of the older population confirm that increased physical activity improves muscular strength and balance, and the risk of falls decreases. The proper diet can largely prevent frailty. Early diagnosis of comorbidities ensures better opportunities for preventing the consequences of frailty syndrome. ${ }^{13}$

Several studies have shown a potential association between nutrition and frailty. Low energy and protein intake and low level of serum nutrients are positively associated with frailty. ${ }^{14,15}$ Malnutrition (both undernutrition and obesity) plays an important role in the pathogenesis of frailty and sarcopenia. ${ }^{16}$

The main aim of this study was to assess the frailty syndrome in relation to the nutritional status of older adults.

We formulated the following questions to be answered by our research:

1. What is the nutritional status of patients on the basis of the Mini Nutritional Assessment (MNA)?

2. What is the frailty status of patients according to SHARE-FI?

3. What sociodemographic factors have an influence on the frailty and nutritional assessment in the study group?

4. Is there a correlation between the frailty and nutritional status?

\section{Material and methods}

This cross-sectional prospective study was conducted between January 2017 and May 2017 including relevant 
anthropometric measurements and muscle strength measurement using a dynamometer. The study comprises a short interview to gather social and demographic data. The study group comprised 120 patients of a Geriatrics Clinic in Bydgoszcz, Poland. The data were collected by an educational nurse. All the participants had been informed of the purpose of the study and the potential risk before signing the consent, approved by the BioEthical Committee at the Nicolaus Copernicus University, Collegium Medicum in Bydgoszcz. This study was conducted in accordance with the Declaration of Helsinki.

The inclusion criteria were: age of 60 and over and signing a written consent to participate in the study. The exclusion criteria were: severe or moderate dementia, depression, weakening muscular strength caused by limb paresis or rheumatoid diseases and the lack of consent. Examination was voluntary. The sample selection was random.

The frailty syndrome was measured using a Polish version of the SHARE-FI, including the measurement of upper limbs' muscle strength using a manual hydraulic dynamometer SAEHAN. The SHARE-

FI instrument classified a subject as frail, prefrail or robust. According to the SHARE-FI results, patients were classified as frail if their score was more than 3 for men and more than 2.13 for women; pre-frail, if the score was between 1.21 and 3 for men and between 0.32 and 2.13 for women; not frail, if the score was $<1.21$ for men and $<0.32$ for women. ${ }^{17}$ The SHARE-FI was operationalized on the basis of Fried's frailty phenotype. $^{3,18}$ The SHARE-FI was also adapted into Polish and a relevant electronic calculator was created. The results of this study showed that the Polish version of SHARE-FI has high internal consistency and reliability coefficients and can be recommended for screening among $60+$ older adults in primary care and hospital settings. In the study, Cronbach's alpha coefficient was $0.79 .{ }^{19}$

The scale consists of five questions regarding exhaustion, loss of appetite, weakness, walking difficulties and low physical activity.

The nutritional status was assessed using the MNA, which measures the risk of malnutrition in older adults and is a combination of a physical examination and dietary survey. The full version of this questionnaire includes elements of a dietary survey and questions concerning the health status, ie, the number/amount and quality of meals and liquids one has a day, mobility, pressure sores or ulcers, neuropsychological problems, the loss of body mass and intensive stress or an acute disease within the last 3 months. MNA also includes self-evaluation of nutrition and health status. The MNA is complemented by somatometric evaluation (the measurement of patients' height and body weight, body mass index (BMI), as well as calf and arm circumference). The test helps identify three groups of patients. Nutritional status is assessed as good if the person scores 24 points or more. Scores between 17 and 23.5 points suggest the threat of malnutrition, and the score $<17$ points reflects malnutrition. ${ }^{20}$

\section{Statistical analysis}

We described the characteristics of the participants using descriptive statistics. The means, along with the SDs, were calculated. We used the $\chi^{2}$ test to assess the association between two variables and the Cramer's V coefficient to determine the strength of this association. Student's $t$ test was used to calculate the confidence level for the mean. For statistical analyses, we used the Statistica 12.0 program. $p$-values lower than 0.05 were considered as statistically significant.

\section{Results}

The mean age of the participants was 71 years $(\mathrm{SD}=9.03)$. The characteristics of the study group are presented in Table 1.

More than half of the participants (64.2\%) had a normal nutritional state but $34.9 \%$ suffered from malnutrition or were at risk of malnutrition. There was a statistically significant difference between male and female in terms of MNA scores $(p=0.026)$. Mean MNA scores in particular age groups did not display any statistical differences and were 24.4 points on average. The risk of malnutrition and malnutrition was higher among rural than urban residents $(p=0.046)$. A statistically significant difference in MNA score was observed in terms of financial standing ( $p=0.016$ ). A higher mean ( 25.2 points) was observed in the group with good financial standing than in the group with average financial standing (23.7 points). No statistically significant correlation was found between the level of education, marital status, duration of illness, number of diseases, number of medicines and MNA scores. The main categories of nutritional assessment are presented in Table 2.

The SHARE-FI qualified 48 persons $(40.0 \%)$ as nonfrail, 40 persons $(33.3 \%)$, were qualified as frail and 32 persons $(26.7 \%)$ as pre-frail. The participants' age 
Table I Characteristics of participants $(n=120)$

\begin{tabular}{|c|c|c|c|}
\hline Category & $\begin{array}{c}\text { Mean/ } \\
\text { SD }\end{array}$ & $\mathbf{n}$ & $\%$ \\
\hline Age & $71 / 9.03$ & & \\
\hline Male & $68.8 / 8.1$ & & \\
\hline Female & $73 / 9.3$ & & \\
\hline Sex & & & \\
\hline Male & & 56 & 46.7 \\
\hline Female & & 64 & 53.3 \\
\hline Marital status & & & \\
\hline Married & & 75 & 62.5 \\
\hline Widow/widower/single & & 45 & 37.5 \\
\hline Family composition & & & \\
\hline Living alone & & 31 & 25.8 \\
\hline Living with family & & 89 & 74.2 \\
\hline Education & & & \\
\hline I-8 years & & 21 & 17.5 \\
\hline $9-12$ years & & 68 & 56.7 \\
\hline $12+$ years & & 31 & 25.8 \\
\hline Financial status & & & \\
\hline Very good & & 3 & 2.5 \\
\hline Good & & 53 & 44.2 \\
\hline Average & & 60 & 50.0 \\
\hline Bad & & 4 & 3.3 \\
\hline Place of living & & & \\
\hline Urban residents & & 101 & 84.2 \\
\hline Rural residents & & 19 & 15.8 \\
\hline Number of diseases & & & \\
\hline $\mathrm{I}-2$ & & 37 & 30.8 \\
\hline 3 or more & & 83 & 69.2 \\
\hline ICD-I0 diagnostic category & & & \\
\hline Diseases of the circulatory system & & & 58.0 \\
\hline Diseases of the respiratory system & & & 28.5 \\
\hline Diseases of the musculoskeletal system & & & 26.7 \\
\hline and connective tissue & & & \\
\hline Endocrine, nutritional and metabolic & & & 24.9 \\
\hline disease & & & \\
\hline Symptoms, signs and abnormal clinical and & & & 10.9 \\
\hline laboratory findings, not elsewhere & & & \\
\hline classified & & & \\
\hline Number of medicines & & & \\
\hline $\mathrm{I}-5$ & & 80 & 66.6 \\
\hline 6 or more & & 40 & 33.4 \\
\hline Duration of illness & & & \\
\hline $\mathrm{I}-15$ years & & 85 & 70.8 \\
\hline Over 15 years & & 35 & 29.2 \\
\hline Use of glasses (yes) & & 81 & 67.5 \\
\hline Use of hearing aid (yes) & & 5 & 4.1 \\
\hline Use of locomotion aid (yes) & & 18 & 15.0 \\
\hline
\end{tabular}

was not statistically significantly correlated with the categories of the frailty syndrome. The SHARE-FI contains a measurement of the grip strength. A higher mean result
Table 2 Nutritional assessment according to MNA - the main categories

\begin{tabular}{|l|l|l|l|}
\hline Category & Mean/SD & $\mathbf{n}$ & $\%$ \\
\hline Mini Nutritional Assessment & $24.4 / 3.4$ & & \\
Male* & $25.2 / 3.2$ & & \\
Female* & $23.7 / 3.5$ & & \\
$<\mid 7$ & & 5 & 4.2 \\
I7-23.5 & & 38 & 31.7 \\
$\geq 24$ & $28.2 / 5.1$ & 77 & 64.2 \\
Body Mass Index & $28.0 / 4.3$ & & \\
Male & $28.4 / 5.8$ & & \\
Female & & $n$ & $\%$ \\
Mid-rm circumference (MAC) in cm & & 9 & 7.5 \\
MAC <2I & & 2 & 1.7 \\
MAC 2I to 22 & & 109 & 90.8 \\
MAC >22 & & & \\
Calf circumference (CC) in cm & & 21 & 17.5 \\
CC <3I & & 99 & 82.5 \\
CC 3I or greater & & & \\
Financial status & & \\
Good ** & $25.2 / 2.7$ & \\
Average** & $23.7 / 3.8$ & & \\
\hline
\end{tabular}

Notes: $* p=0.026 ; * * p=0.016$.

was noted in the group of male $(p<0.001)$ than female. The results are presented in Table 3.

No statistically significant correlation was found between age, level of education, marital status, place of living, duration of illness, number of diseases, number of medicines and SHARE-FI scores. A statistically significant difference in SHARE-FI score was observed in terms of financial standing $(p=0.036)$ and gender $(p<0.025)$. Good financial standing is associated with non-frail status of patients. SHARE-FI score and MNA results according to gender are presented in Table 4.

There was, however, a statistically significant difference between the groups of MNA scores and the frailty syndrome $(p<0.01)$. Malnutrition was correlated with frailty. The results are shown in Table 5.

The highest number of patients, 82 persons $(68.3 \%)$, declared doing some physical activity once a week.

\section{Discussion}

Frailty syndrome as a geriatric problem is connected with a high likelihood of reduced functional capability, occurrence of falls, disability, morbidity and higher mortality. ${ }^{21}$ The costs of care and hospitalization are increasing. The results of frailty also reduce the level of independence, quality of life and mental well-being of the older adults. ${ }^{22}$ Caregivers, 
Table 3 Frailty assessment according to Frailty Instrument of the Survey of Health, Ageing and Retirement in Europe (SHARE-FI)

\begin{tabular}{|c|c|c|}
\hline SHARE-FI & $\mathbf{n}$ & $\%$ \\
\hline Non-frail & 48 & 40 \\
\hline Pre-frail & 32 & 26.7 \\
\hline Frail & 40 & 33.3 \\
\hline Total & 120 & 100 \\
\hline \multicolumn{3}{|l|}{ Exhaustion } \\
\hline Yes & 40 & 33.3 \\
\hline No & 80 & 66.6 \\
\hline \multicolumn{3}{|l|}{ Loss of appetite } \\
\hline $\begin{array}{l}\text { Diminution in desire for food and/or eating less than } \\
\text { usual }\end{array}$ & 29 & 24.2 \\
\hline $\begin{array}{l}\text { No change in desire for food and/or eating the same } \\
\text { as usual }\end{array}$ & 81 & 67.5 \\
\hline $\begin{array}{l}\text { Increase in desire for food and/or eating more than } \\
\text { usual } \\
\text { Walking difficulties }\end{array}$ & 10 & 8.3 \\
\hline Walking 100 m: yes & 86 & 71.7 \\
\hline Walking 100 m: no & 34 & 28.3 \\
\hline \multicolumn{3}{|l|}{ Climbing one flight of stairs without resting } \\
\hline Yes & 75 & 62.5 \\
\hline No & 45 & 37.5 \\
\hline \multicolumn{3}{|l|}{ Low physical activity } \\
\hline Hardly ever or never & 20 & 16.7 \\
\hline One to three times a month & 9 & 7.5 \\
\hline Once a week & 82 & 68.3 \\
\hline More than once a week & 9 & 7.5 \\
\hline Weakness & Mean & SD \\
\hline \multicolumn{3}{|l|}{ Maximum grip strength in kilograms } \\
\hline \multicolumn{3}{|l|}{ I attempt right hand } \\
\hline Men & 33.21 & 9.3 \\
\hline Women & 18.0 & 6.1 \\
\hline Total & 25.1 & 10.8 \\
\hline \multicolumn{3}{|l|}{ II attempt right hand } \\
\hline Men* & 35.23 & 9.3 \\
\hline Women* & 18.66 & 6.2 \\
\hline \multicolumn{3}{|l|}{ Il attempt left hand } \\
\hline Men* & 33.18 & 10.8 \\
\hline Women* & 16.92 & 5.4 \\
\hline Total & 24.51 & 11.7 \\
\hline \multicolumn{3}{|l|}{ II attempt left hand } \\
\hline Men* & 34.02 & 10.8 \\
\hline Women* & 17.69 & 5.2 \\
\hline Total & 25.31 & 11.6 \\
\hline
\end{tabular}

Note: ${ }^{*} p<0.001$.

families, general and geriatric health care and social welfare are involved in the care of frail older adults. This problem has already been recognized in many countries, and some solutions have been proposed to improve diagnostics as well as preventive and therapeutic measures. ${ }^{23}$
Table 4 SHARE-FI score and MNA results according to gender

\begin{tabular}{|l|l|l|l|l|}
\hline Gender & \multicolumn{3}{|l|}{ Male } & \multicolumn{2}{l|}{ Female } \\
\hline SHARE-FI & $\mathbf{n}$ & $\%$ & $\mathbf{n}$ & $\%$ \\
\hline Non-frail* & 30 & 53.6 & 18 & 28.1 \\
Pre-frail* & 14 & 25.0 & 18 & 28.1 \\
Frail* & 12 & 21.4 & 28 & 43.8 \\
MNA & $\mathrm{n}$ & $\%$ & $\mathrm{n}$ & $\%$ \\
$<17^{* *}$ & 2 & 3.6 & 3 & 4.7 \\
I7-23.5** & 12 & 21.4 & 26 & 40.6 \\
$\geq 24^{* *}$ & 43 & 75.0 & 34 & 54.7 \\
Total & 56 & 100.0 & 64 & 100.0 \\
\hline
\end{tabular}

Notes: ${ }^{*} p<0.025$ Cramer coefficient 0.28 ; $* *=0.026$ Cramer coefficient 0.2 I. Abbreviations: SHARE-Fl, Frailty Instrument of the Survey of Health, Ageing and Retirement in Europe; MNA, Mini Nutritional Assessment.

Table 5 Correlation between SHARE-FI score and MNA results

\begin{tabular}{|l|l|l|l|l|l|l|}
\hline MNA results & \multicolumn{2}{|l|}{$<\mathbf{1 7 p}$} & \multicolumn{2}{l|}{$\mathbf{I 7 - 2 3 . 5}$} & \multicolumn{2}{l|}{$\geq \mathbf{2 4}$} \\
\hline SHARE-FI & $\mathbf{n}$ & $\%$ & $\mathbf{n}$ & $\%$ & $\mathbf{n}$ & $\%$ \\
\hline Non-frail* & $\mathrm{I}$ & 20.0 & 8 & 21.1 & 39 & 50.6 \\
Pre-frail* & 0 & 0.0 & 10 & 26.3 & 22 & 28.6 \\
Frail* & 4 & 80.0 & 20 & 52.6 & 16 & 20.8 \\
Total & 5 & 100.0 & 38 & 100.0 & 77 & 100.0 \\
\hline
\end{tabular}

Note: $*_{p}<0.01$ Cramer coefficient 0.37 .

Abbreviations: SHARE-FI, Frailty Instrument of the Survey of Health, Ageing and Retirement in Europe; MNA, Mini Nutritional Assessment.

The aim of our study was to assess the frailty syndrome in relation to nutritional status of older adults. The study was carried out among 120 people aged 60 years and over. The results of the study showed that in the group of older adults, 40 hospitalized persons $(33.3 \%)$ met the criteria of diagnosing frailty syndrome according to the SHARE-FI and 32 persons (26.7\%) were diagnosed as pre-frail. A statistically significant difference was found between women and men in terms of the categories of the frailty syndrome scale. In the study sample, more women than men met the criteria but participants' age was not statistically significant. However, in the group of very advanced age, there were more individuals with the frailty syndrome than in relatively younger groups. A study by Lubińska et al showed that most people qualified as frail were older adults, more often women, from poorer circles and with lower education levels. ${ }^{24}$ Frailty syndrome is a serious problem in geriatrics, which requires further research concerning its diagnostics and the possibility of primary and secondary prevention.

In our study using the MNA more than half of the participants have a normal nutritional status, but over onethird obtained scores indicated malnutrition or the risk of 
malnutrition: $43.9 \%$. The mean MNA score was 24.4 points. A higher mean of MNA scores was observed in the group of men than in the group of women. No differences were found in the MNA score depending on the participants' age, but the risk of malnutrition and malnutrition were significantly higher in rural than urban residents. Financial situation also affected the MNA rate, which was higher in the group with good financial standing. The mean outcomes of measurements of arm and calf circumference were within the norm.

In our study, a statistically significant difference was found between the groups of MNA scores and the frailty syndrome $(p<0.01)$, with malnutrition correlated with frailty. Chang also reported a high significance of frailty syndrome for the high risk of malnutrition in communitydwelling older people. ${ }^{25}$ In another study, the same author found that pre-frailty and body mass index were independently correlated with the nutritional status of the participants. $^{26}$ According to Valentini et al research, about $38 \%$ of the study was frail, with the prevalence of frailty being greater among hospitalized older patients and among frail subjects, $65 \%$ were at risk of malnutrition and $10 \%$ were malnourished. ${ }^{27}$

According to other authors, the prevalence of frailty was highest among people who were obese (20.8\%), overweight (18.4\%), normal weight (16.1\%) and lowest among people who were underweight $(13.8 \%) .{ }^{28}$ Malnutrition causes the development of many life-threatening complications. In chronically ill patients, malnutrition leads to prolonged treatment, and it may cause many complications and has an influence on prognosis. Malnutrition in older adults also leads to the worsening of peristalsis and to impaired absorption and digestion. Malnourished patients often suffer from hypovitaminosis. The state of deficiency of basic nutrients leads to the atrophy of respiratory muscles. Ventilation function of such patients worsens, often leading to pneumonia, which is especially dangerous. Improper nutrition of geriatric patients is a factor that increases morbidity and mortality, and depression is another common problem among older adults. Clinical studies show that even $30 \%$ malnutrition cases are connected with depression. ${ }^{29,30}$ Malnutrition plays an important role in the pathogenesis of frailty syndrome and sarcopenia, leads to age-related loss of muscle mass and reduces physical activity. ${ }^{16}$

Our research shows a statistically significant difference between men and women with regard to the nutritional state. In men, the mean MNA score was higher than in women. There was also a statistically significant difference between financial standing groups. Higher MNA scores were found in the group with good financial standing. People with a good financial situation have more opportunities to buy good food products.

Studies of other authors also pay attention to the relation between gender and financial status and the MNA score. According to Mirczak, both sex and poor financial status are factors that promote malnutrition in older adults $(p<0.05))^{31}$ Our study confirmed these outcomes.

An important diagnostic criterion of frailty is the measurement of the grip muscle strength, in this study measured with a dynamometer. The mean grip strength in the right parent hand in the first and second attempts was $25.1 \mathrm{~kg} / 26.39 \mathrm{~kg}$ for the study group. The results of the second attempt were on average higher than in the first one. In our study, we observed greater weakness of muscle strength in women than in men, but the general outcome in the study group was good. Muscle weakness is defined as low when the grip strength is lower than $26 \mathrm{~kg}$ for men and lower than $16 \mathrm{~kg}$ for women. ${ }^{32}$ In the study of other authors, the criterion of weakness measured with the grip strength was met by $70 \%$ of the participants. Muscular strength weakness was positively correlated with the results of Instrumental Activity of Daily Living (IADL), Mini-Mental State Examination (MMSE), Barthel Index, Geriatric Depression Scale (GDS), the level of C-reactive protein and the Visual Analog Scale score. ${ }^{32}$ Other authors emphasize the relation between muscle weakness in older patients and increased direct financial expenditure on the provision of care. In this case, muscular weakness had a significant influence on direct costs of care, especially for women. ${ }^{33}$

Physical activity of the participants was quite low, as most of them declared doing some activity once a week $(68.3 \%)$ or no activity at all $(16.7 \%)$, and only $7.5 \%$ reported they exercised regularly. In a longitudinal observation study of older patients admitted to home care programs at the Italian Silver Network Home Care project in Italy, $20 \%$ of participants were physically active for $2 \mathrm{hrs}$ a week or more. The obtained results confirm the significance of physical activity in reducing the risk of death for any reason. Research results confirm that moderate physical activity has an independent influence on survival, even in frail and older people. ${ }^{34}$

The present study confirms the hypothesis that frailty syndrome is correlated to the status of nutrition, with malnutrition correlated with frailty. The participants' age, 
education and place of residence were not statistically significantly correlated with the results of frailty categories for the whole sample. Gender and financial standing was statistically significantly correlated with the results of frailty categories and MNA results. In the group of people with medium financial standing, the highest number of people was in the frail category, whereas in the group with good financial standing, the highest number was in the non-frail category. In the prevention of frailty syndrome, it would be important to increase physical activity among older adults. Another important thing would be to focus on the quality of nutrition of older adults to improve individual parameters and the general outcome of the MNA scale. It would be important to help raise older adults' awareness of the consequences of malnutrition. It would also be necessary to focus on the group of women, who display a higher risk of malnutrition and higher risk of frailty syndrome.

\section{Limitations}

The limitation of our study may be to perform it in one place, in the hospital. However, the structure of the study group was representative for patients admitted to the clinic for various reasons. Study of the nutritional status and the frailty should be standard for comprehensive geriatrics assessment. Whereas, the examination of the relationship between nutrition and frailty is essential for planning wider assessment, treatment and care. Our study is just an introduction to further research in this regard. We are aware that it must be continued and widened, so further stages of research are planned, with the inclusion of biochemical tests and exploration of the importance of genetic tests in search of a molecular basis for the frailty syndrome among older adults.

\section{Conclusions}

A significant difference was found between the groups of MNA scores and the frailty syndrome, with malnutrition correlated with frailty. The frailty syndrome occurred in one-third of the participants and gender was statistically significantly correlated. In addition, there was a statistically significant difference between women and men in terms of MNA scores. In the group of men, the mean MNA score was higher than in the group of women. Malnutrition was higher among rural than urban residents and in the group with poorer financial standing.

\section{Acknowledgments}

We would like to thank all the participants of the test and the nurses who were willing to support us while the research. This work was founded by statutory grant of research topic WN721. The name and degree of the manager statutory grant of research- dr hab Marta Muszalik.

\section{Disclosure}

The authors report no conflict of interest in this work.

\section{References}

1. Walston J, Hadley EC, Ferrucci L, et al. Research agenda for frailty in older adults: toward a better understanding of physiology and etiology: summary from the American Geriatrics Society/National Institute on Aging Research Conference on Frailty in Older Adults. $J$ Am Geriatr Soc. 2006;54(6):991-1001. doi:10.1111/j.15325415.2006.00745.x

2. Chen X, Mao G, Leng SX. Frailty syndrome: an overview. Clin Interv Aging. 2014;9:433-441. doi:10.2147/CIA.S45300

3. Ortuno RR, Walsh CD, Lawlor BA, Kenny RA. A Frailty Instrument for primary care: findings from the Survey of Health, Ageing and Retirement in Europe (SHARE). BMC Geriatr. 2010. doi:10.1186/ 1471-2318-10-57

4. Hoogendijk E, Deeg DJ, Poppelaars J, et al. Study Amsterdam: cohort update 2016 and major findings. Eur J Epidemiol. 2016;31 (9):927-945. doi:10.1007/s10654-016-0192-0

5. Fried LP, Tangen CM, Walston J, et al. Frailty in older adults: evidence for a phenotype. J Gerontol A Biol Sci Med Sci. 2001;56 (3):M146-M156. doi:10.1093/gerona/56.3.M146

6. Sánchez-Flores M, Marcos-Pérez D, Costa S, et al. Oxidative stress, genomic features and DNA repair in frail elderly: A systematic review. Ageing Res Rev. 2017;37:1-15. doi:10.1016/j.arr.2017.05.001

7. Mitnitski AB, Mogilner AJ, Rockwood K. Accumulation of deficits as aproxy measure of aging. Sci World J. 2001;1:323-336. doi:10.1100/tsw.2001.58

8. Rockwood K, Song X, MacKnight C, et al. A global clinical measure of fitness and frailty in elderly people. Can Med Assoc J. 2005;173:489-495. doi:10.1503/cmaj.050051

9. Życzkowska J, Grądalski T. Zespół słabości - co powinien o nim wiedzieć onkolog? [Frailty syndrome- what an oncologist should know]. Onkol Prakt Klin. 2010;6(2):79-84. Polish.

10. Dubiel M, Grodzicki T. Zespół słabości i jego potencjalne znaczenie w leczeniu chorób układu krążenia [Frailty syndrome and its potential significance in treatment of cardiovascular diseases]. Med Dypl. 2009;18(9):41-53. Polish.

11. Lee DR, Santo EC, Lo JC, Ritterman Weintraub ML, Patton M, Gordon NP. Understanding functional and social risk characteristics of frail older adults: a cross-sectional survey study. BMC Fam Pract. 2018;19(1):170. doi:10.1186/s12875-018-0851-1

12. Chamberlain AM, Sauver JLS, Jacobson DJ, et al. Social and behavioural factors associated with frailty trajectories in a population-based cohort of older adults. BMJ Open. 2016;6(5): e011410. doi:10.1136/bmjopen-2016-011410

13. Bujnowska-Fedak MM, Waligóra J, D’Avanzo B, Holland C, Kurpas D. Approaches to therapy and prevention of frailty in the light of contemporary medicine. Fam Med Prim Care Rev. 2017;19 (3):289-297. doi:10.5114/fmpcr.2017.69293

14. Bartali B, Frongillo EA, Bandinelli S, et al. Low nutrient intake is an essential component of frailty in older persons. J Gerontol A Biol Sci Med Sci. 2006;61:589-593. doi:10.1093/gerona/61.6.589

15. Beasley JM, La Croix AZ, Neuhouser ML, et al. Protein intake and incident frailty in the Women's Health Initiative observational study. $J$ Am Geriatr Soc. 2010;58:1063-1071. doi:10.1111/j.15325415.2010.03135.x 
16. Cruz-Jentoft AJ, Kiesswetter E, Drey M, Sieber CC. Nutrition, frailty, and sarcopenia. Aging Clin Exp Res. 2017;29(1):43-48. doi:10.1007/s40520-016-0709-0

17. Santos-Eggimann B, Cuenoud P, Spagnoli J, Junod J. Prevalence of frailty in middle-aged and older community-dwelling Europeans living in 10 countries. J Gerontol A Biol Sci Med Sci. 2009;64 (6):675-681. doi:10.1093/gerona/glp012

18. Ortuno RR. The Frailty Instrument for primary care of the Survey of Health, Ageing and Retirement in Europe predicts mortality similarly to a frailty index based on comprehensive geriatric assessment. Geriatr Gerontol Int. 2013;13(2):497-504. doi:10.1111/j.14470594.2012.00948.x

19. Muszalik M, Borowiak E, Kotarba A, Puto G, Doroszkiewicz H, Kędziora-Kornatowska K. Adaptation and reliability testing of the SHARE-FI instrument for the assessment of risk of frailty syndrome among older Polish patients. Fam Med Prim Care Rev. 2018;20 (1):36-40. doi:10.5114/fmpcr.2018.73702

20. Kostka J, Borowiak E, Kostka T. Validation of the modified mini nutritional assessment short-forms in different populations of older people in Poland. $J$ Nutr Health Aging. 2014;18(4):366-371. doi:10.1007/s12603-013-0393-0

21. Bagshaw SM, Stelfox HT, Johnson JA, et al. Long-term association between frailty and health-related quality of life among survivors of critical illness: a prospective multicenter cohort study. Crit Care Med. 2015;43(5):973-982. doi:10.1097/CCM.0000000000000860

22. Cano A, Kurpas D, Bujnowska-Fedak MM, et al. FOCUS: frailty management optimization through EIPAHA commitments and utilization of stakeholders' input - an innovative European Project in elderly care. Fam Med Prim Care Rev. 2016;18(3):373-376. doi:10.5114/fmpcr/63234

23. Ritt M, Ritt JI, Sieber CCH, Günter Gaßmann K. Comparing the predictive accuracy of frailty, comorbidity, and disability for mortality: a 1-year follow-up in patients hospitalized in geriatric wards. Clin Interv Aging. 2017;12:293-304. doi:10.2147/CIA.S124342

24. Lubińska A, Popiel A, Sokołowski R. Diagnosis of the frailty syndrome. J Health Sci. 2013;3(9):2017-2320.

25. Chang SF, Lin PL. Prefrailty in community-dwelling older adults is associated with nutrition status. J Clin Nurs. 2016;25(3-4):424-433. doi:10.1111/jocn. 13063
26. Chang SF. Frailty is a major related factor for at risk of malnutrition in community dwelling older adults. J Nurs Scholarsh. 2017;49 (1):63-72. doi:10.1111/jnu. 12258

27. Valentini A, Federici M, Cianfarani MA, Tarantino U, Bertoli A. Frailty and nutritional status in older people: the Mini Nutritional Assessment as a screening tool for the identification of frail subjects. Clin Interv Aging. 2018;13:1237-1244. doi:10.2147/CIA. $\mathrm{S} 164174$

28. Smit E, Winters-Stone KM, Loprinzi PD, Tang AM, Crespo CJ. Lower nutritional status and higher food insufficiency in frail older US adults. $B r \quad J$ Nutr. 2013;110(1):172-178. doi:10.1017/ S000711451200459X

29. Ahmed T, Haboubi N. Assessment and management of nutrition in older people and its importance to health. Clin Interv Aging. 2010;5:207-216.

30. Krzymińska-Siemaszko R, Wieczorowska-Tobis K. Evolution of the malnutrition assessment among elderly patients. Geriatria. 2012;6:139-143. Polish.

31. Mirczak A. Czynniki determinujące ryzyko niedożywienia osób starszych ze środowiska wiejskiego [Factors determining the risk of malnutrition of the elderly from the rural environment]. Med Srod. 2014;17(4):68-75. Polish.

32. Dudzińska-Griszek J, Szuster K, Szewieczek J. Grip strength as a frailty diagnostic component in geriatric inpatients. Clin Interv Aging. 2017;12:1151-1157. doi:10.2147/CIA.S140192

33. Steffl M, Sima J, Shiells K, Holmerova I. The increase in health care costs associated with muscle weakness in older people without long-term illnesses in the Czech Republic: results from the Survey of Health, Ageing and Retirement in Europe (SHARE). Clin Interv Aging. 2017;12:2003-2007. doi:10.2147/CIA. S 150826

34. Landi F, Cesari M, Onder G, Lattanzio F, Gravina EM, Bernabei R. Physical activity and mortality in frail, community-living elderly patients. J Gerontol A Biol Sci Med Sci. 2004;59(8):833-837.
Clinical Interventions in Aging

\section{Publish your work in this journal}

Clinical Interventions in Aging is an international, peer-reviewed journal focusing on evidence-based reports on the value or lack thereof of treatments intended to prevent or delay the onset of maladaptive correlates of aging in human beings. This journal is indexed on PubMed Central, MedLine, CAS, Scopus and the Elsevier
Bibliographic databases. The manuscript management system is completely online and includes a very quick and fair peer-review system, which is all easy to use. Visit http://www.dovepress.com/ testimonials.php to read real quotes from published authors. 